Review

\title{
Nature and role of root exudates: Efficacy in bioremediation
}

\author{
Keshav Prasad Shukla, Shivesh Sharma*, Nand Kumar Singh, Vasudha Singh, Kirti Tiwari \\ and Sphoorti Singh
}

Department of Applied Mechanics (Biotechnology), Motilal Nehru National Institute of Technology, Allahabad (UP), India.

Accepted 13 July, 2011

\begin{abstract}
Root exudate is one of the ways for plant communication to the neighboring plant and adjoining of microorganisms present in the rhizosphere of the root. The chemicals ingredients of the root exudates are specific to a particular plant species and also depend on the nearby biotic and abiotic environment. The chemical ingredient exuded by plant roots include amino acids, sugars, organic acids, vitamins, nucleotides, various other secondary metabolites and many other high molecular weight substances as primarily mucilage and some unidentified substances. Through the exudation of a wide variety of compounds, roots may regulate the soil microbial community in their immediate vicinity, cope with herbivores, encourage beneficial symbioses, change the chemical and physical properties of the soil and inhibit the growth of competing plant species. Root exudates mediate various positive and negative interactions like plant-plant and plant-microbe interactions. The present review has been undertaken to examine the possible role of root exudates on the removal of the polluted matter and nourishing the neighboring microorganisms present in the rhizosphere of the root.
\end{abstract}

Key words: Rhizosphere, root exudates, bioremediation, rhizoremediation.

\section{INTRODUCTION}

Unseen part of the plant secretes chemical compounds which acts as communication signal between the adjacent plant and microbial community present in the rhizosphere of the root. Root exudates correspond to an important source of nutrients for microorganisms in the rhizosphere and seem to participate in early colonization inducing chemotactic responses of rhizospheric bacteria (Bacilio et al., 2002). Rhizosphere is defined as a zone of most intense bacterial activity around the roots of plant (Hiltner, 1904). However, for the sake of practical investigation, the rhizosphere is most often defined as the soil adhering to plant roots when they are rigorously shaken, throughout which the rhizosphere effect must be observed to some extent (Kang and Mills, 2004). A survey of the literature exposes an extensive range of compounds exuding from intact and healthy roots; these include sugars, amino acids, peptides, enzymes,

*Corresponding author. E-mail: shiveshs@mnnit.ac.in or sharmashivesh@email.com. vitamins, organic acids, nucleotides, fungal stimulators, inhibitors and attractants, eelworm hatching and attracting factors and many miscellaneous compounds. Organic acids, sugars, amino acids, lipids, coumarins, flavonoids, proteins, enzymes, aliphatics and aromatics are examples of the primary substances found within rhizosphere of the root. Among them, the organic acids have received considerable attention due to their role in providing substrates for microbial metabolism and for serving as intermediates for biogeochemical reactions in soil (Philippe, 2006).

The field of rhizosphere biology has find out the relative importance of root exudates in mediating interactions with neighboring plants and microbes (Bais, 2004, 2006; Weir et al., 2004; Broeckling et al., 2008). Root exudation is an element of the rhizodeposition process, which is a major source of soil organic carbon released by plant roots (Hutsch et al., 2000; Nguyen, 2003). Upon assembling a challenge, roots typically respond by secreting certain small molecules and proteins (Stintzi et al., 2000; Stotz, 2000). Root secretions may play both positive and negative communication in the rhizosphere. The positive 
communication includes symbiotic associations with beneficial microbes, such as mycorrhizae, rhizobia and plant growth promoting rhizobacteria (PGPR). Negative interactions include association with parasitic plants, pathogenic microbes and invertebrate herbivores. The rhizospheric bacteria are responsible for the elimination of the contaminants while the roots are responsible for providing nutrients (root exudates) used by the microorganisms to proliferate (Bais et al., 2008).

Selected microbes can degrade most environmental pollutants. The process stops when the microbe is starved of food. In order to determine that such microbes can have access to the best food source available in soil, workers have described an enrichment method for the isolation of microbes, which combine the properties of: (1) degradation of a selected pollutant and (2) excellent root colonization. Shukla et al. (2010) illustrated the process 'rhizoremediation' to emphasize the roles of the root exudates and the rhizosphere competent microbes.

The objectives of this review are therefore to: highlight the type, chemical nature, factors affecting the root exudates; provide an insight in to the role of various interactions of the root exudates with the root of other plant and root microbe interaction; and explore the current concepts and the possible application of root exudates in the cleaning of environment through rhizoremediation.

\section{CHEMICAL NATURE AND COMPOSITION OF ROOT EXUDATES}

In general, the component of carbohydrates compounds extracted by the root is arabinose, glucose, galactose, fructose, sucrose, pentose, rhamnose, raffinose, ribose, xylose and mannitol. Current evidence suggests that sugars such as glucose dominate root exudates (Jones and Darrah, 1995; Lugtenberg, 1999; Toal, 2000). All 20 proteinogenic amino acids, I-hydroxyproline, homoserine, mugineic acid, and aminobutyric acid are included in amino acids exudates. Acetic acid, succinic acid, Iaspartic acid, malic acid, I-glutamic acid, salicylic acid, shikimic acid, isocitric acid, chorismic acid, sinapic acid, caffeic acid, $p$-hydroxybenzoic acid, (Alexa et al., 2004) gallic acid, tartaric acid, ferulic acid, protocatacheuic acid, p-coumaric acid, mugineic acid, oxalic acid, citric acid, and piscidic acid are categorized in organic acids and phenolic compounds (Jeremy et al., 2004). Some of these compounds, especially the phenolics, influence the growth and development of surrounding plants and soil microorganisms. Naringenin, kaempferol, quercitin, myricetin, naringin, rutin, genistein, strigolactone and their substitutes with sugars are the flavonols (Antonio et al., 2009; Siegridet al., 2007).

Catechol, benzoic acid, nicotinic acid, phloroglucinol, cinnamic acid, gallic acid, ferulic acid, syringic acid are derivatives of lignin (Dayakar et al., 2009), sinapoyl aldehyde, chlorogenic acid, coumaric acid, vanillin, sinapyl alcohol, quinic acid, pyroglutamic acid. Coumarins (Umbelliferone), aurones (benzyl aurones synapates, sinapoyl choline), glucosinolates (cyclobrassinone, desuphoguconapin, desulphoprogoitrin, desulphonapoleiferin, desulphoglucoalyssin), anthocyanins (cyanidin, delphinidin, pelargonidin and their substitutes with sugar molecules), indole compounds (indole-3-acetic acid, brassitin, sinalexin, brassilexin, methyl indole carboxylate, camalexin glucoside), fatty acids (linoleic acid, oleic acid, palmitic acid, stearic acid), sterols (campestrol, sitosterol, stigmasterol), allomones (jugulone, sorgoleone, 5,7,4'-trihydroxy-3', 5'-dimethoxyflavone, DIMBOA, DIBOA) (Bais et al., 2006) and proteins and enzymes (proteins, lectins, proteases, acid phosphatases, peroxidases, hydrolases, lipase) are the compounds found on root exudates, which is isolated from various plant roots (Narasimhan et al., 2003; Uren, 2000).

A research shows that the main carbohydrates secreted from rice (Oryza sativa) identified were glucose, arabinose, mannose, galactose, and glucuronic acid and rice exudates may induce a higher chemotactic response for endophytic bacteria (Corynebacterium flavescens and Bacillus pumilus) than for other bacterial strains (plant growth promoting bacteria, Azospirillum brasilense and Bacillus sp.) present in the rice rhizosphere. Endophytic bacteria appear to be ever-present in most plant species, inducing beneficial effects, as incidental from their ability to promote plant growth (Bacilio et al., 2001) to confer resistance against plant pathogens (Benhamou et al., 1996; Hallmann et al., 1997; Pleban et al., 1995).

\section{FACTORS AFFECTING EXUDATION}

The exudation of organic compounds by roots are influenced by either biotic (for example, soil microbial uptake) (Kuzyakov et al., 2003) or abiotic processes (Hees et al., 2003). In some instances, our knowledge is sufficient to explain why exudation is affected by the root environment, but often our ignorance of the physiological processes involved in exudation precludes a correct explanation. Some of the factors influencing exudation are listed as thus explained:

\section{Plant species}

The amount, range and balance of compounds in root exudates differ for different plant species. Some worker found differences between wheat and barley (Hordeum vulgare L.) root exudates with respect to certain sugars (galactose, glucose and rhamnose), whereas other sugars occurred in similar amounts in exudates of both plants (Vancura, 1964). The specificity of root exudates from different plants in stimulating only certain groups of 
organisms is clearly demonstrated in the plant pathology literature, for example, the cysts of potato eelworm (Heterodera rostochiensis) hatched when supplied the root washings of potato (Solanum tuberosum L.), tomato and some other solanaceous plants, but not the washings of beet (Beta vulgaris L.), rape (Brassica napus L.), lupin (Lupinus lilosus L.), mustard (Brassica sp.) or oats (Xiaoe et al., 2005).

\section{Root age}

Research done with peas and oats indicated that more amino acids and sugars exuded during the first 10 days of growth than during the second 10 days (Rovira, 1956). Vancura and Hovadik, (1965) study found 3pyrazolylalanine in root exudate of cucumber (Cucumis sativus L.) only at the early seeding stage. With tomato and red pepper (Capsicum anznumm L.), they found that tyrosine occurred in the exudate only at fruiting and not at any other stage of growth.

\section{Microorganisms}

Microorganisms may affect the permeability of root cells, metabolism of roots, absorption and excretion of certain compounds in root exudates. It was reported that filtrates of cultures of some bacteria and fungi and also some antibiotics (penicillin), increased the exudation of scopoletin (6 methoxy -7 hydroxycoumarin) by oat roots (Blaylock et al., 1997). Norman (1961) found that certain polypeptide antibiotics, for example, polymyxin which is formed by Bacillus polymyxa from soil, altered cell permeability and increased leakage. There are two main difficulties in interpreting the significance of their results which show that culture filtrates or products increase the leakiness of plant roots. First, the conditions under which the organisms are grown are quite different both physically and nutritionally from those under which a rhizosphere population grows. Second, as it is not possible to calculate the concentration of biologically active substances in the rhizosphere, the concentrations used for "in vitro" experiments must of necessity be selected rather arbitrarily. A further point is that, any consideration of the significance of the rhizosphere population in modifying exudation must involve a concept of micro-ecology, with a wide variety of organisms occupying different "niches on the roots and only those plant cells in the immediate vicinity of "exudation- promoting" organisms are likely to be affected. Microorganisms also influenced the exudation of organic materials into soil. A supplementary study showed that the exudation from wheat roots into synthetic soil was increased at least four fold by microorganisms (Norman, 1961). The magnitude of the effects of microorganisms upon exudation no doubt will depend on the species colonizing the roots (Albert, 1969). Some other plant biotic factors like developmental status, shoot herbivory, photosynthesis, supply of carbon from shoot to root, evaporation, transpiration, nutrient deficiency, root architecture, cytosolic concentration, membrane permeability, membrane electrochemical potential, release of microbial signal, allelochemical release, mychorrhizas, nodulation and some soil biotic factor are also influenced by the root exudation.

\section{Temperature}

The release of amino acids and, especially, asparagine from roots of tomato and subterranean clover (Trifolium subterraneum L.) increased with rising temperature (Rovira, 1959). However, this effect is by no means universal, as some worker found more amino acids in exudates from strawberry plants (Fragatia vesca L.) grown at 5 to $10^{\circ} \mathrm{C}$ than at 20 to $30^{\circ} \mathrm{C}$; this markedly influenced the pathogenicity of (italics) which attacks strawberries at low soil temperatures (Husain and Mckeen, 1963, Hale et al., 1978).

\section{Light}

The light intensity at which plants are growing affects the amounts and balance of compounds exuded into nutrient solution by tomato and subterranean clover roots (Rovira, 1959). Clover grown at full daylight intensity exuded more serine, glutamic acid, and c-alanine than plants grown in $60 \%$ shade. With tomato, the levels of aspartic acid, glutamic acids, phenylalanine and leucine in exudate were reduced by shading. Beside these abiotic factors, few others such as moisture, humidity, wind speed and light intensity, elevated $\mathrm{CO}_{2}$ pesticides, available space, atmosphereic nitrogen deposition, ozone, physical disturbance, fire, irrigation, erosion, altitude and latitude are also influencing the exudation (Torsivik et al., 1996).

Some soil abiotic factors resembling compaction, soil type, salinity, soil $\mathrm{pH}$, metal toxicity, water availability, organic matter, cation and anion exchange, drainage, aeration, rooting depth, soil texture, soil structure and redox-potential influence the release of organic chemical from plant root (Ross et al., 2000; Rangarajan et al., 2001).

\section{INTERACTION STUDIES}

Root-mediated rhizospheric interactions are broadly classified into two categories; positive and negative interactions. Positive interactions involve root exudatemediated interactions with plant growth-promoting rhizobacteria (PGPR). Roots produce chemical signals that attract bacteria and induce chemotaxis (Thimmaraju 
et al., 2008). Positive interactions mediated by root exudates also include growth facilitators that support growth of other plants and also perform cross-species signaling with rhizospheric invertebrates. Contrastingly, negative interactions mediated by root exudates involve secretion of antimicrobials, phytotoxins, nematicidal and insecticidal compounds (Bais et al., 2006).

\section{Root-root communication}

Root exudates may play a straight role as phytotoxins in mediating chemical interference (allelopathy) and significant indirect roles in resource competition by altering soil chemistry, soil processes and microbial populations. Plants that produce and release potent phytotoxins can reduce the establishment, growth or survival of susceptible plant neighbors, thus, reducing competition and increasing resource availability. Plants release phytotoxins in decomposing leaf and root tissue, in leachates from live tissue, in green leafy volatiles, and in root exudates (Bertin et al., 2003). Different phytotoxins in root exudates affect metabolite production, photosynthesis, respiration, membrane transport, germination, root growth, shoot growth and cell mortality in susceptible plants (Weir et al., 2004).

According to a group of study, a variety of phytotoxic compounds are released as root exudates for example 7, 8-benzoflavone [Acroptilon repenst (italics), Russian knapweed], ( \pm )-catechin (Centaurea maculosa, spotted knapweed), DIMBOA and DIBOA (Triticum aestivum, wheat), juglone (Juglans nigra, black walnut), 8hydroxyquinoline (Centaurea diffusa, diffuse knapweed), sorgoleone (Sorghum spp.), and 5, 7, 4'-trihydroxy-3', 5'dimethoxyflavone $(O$. sativa, rice). These compounds possess some structural components, such as aromaticity (with the exception of sorgoleone), hydroxyl and/or ketone groups. However, the structures of the compounds also vary considerably, and include flavonoids [7, 8-benzoflavone, ( \pm -catechin, and 5, 7, 4'tri-hydroxy-3', 5'-dimethoxyflavone], quinones (juglone and sorgoleone), quinolines (8-hydroxyquinoline), and hydroxamic acids (DIMBOA- 2, 4-dihydroxy-7-methoxy-1, 4-benzoxazin-3-one), DIBOA) (Stermitz et al., 2003; Bais et al., 2002; Wu et al., 2000; Jose and Gillespie, 1998; Vivanco et al., 2004; Nimbal et al., 1996; Kong et al., 2004).

One of the oldest classical examples of allelopathy involving root exudation is the growth inhibition caused by the presence of black walnut in the landscape (Bais et al., 2006). Walnut toxicity is associated with the presence of a potent napthoquinone, juglone (5-hydroxy-1, 4napthoquinone). In living tissues, juglone is generally found in a reduced non-toxic form, but when exposed to air it becomes oxidized and thus, toxic. Isolated juglone is orange in color and can be noticed when fresh bark is stripped from roots or fresh fruit hulls are cut (Kocacali et al., 2009). Other trees closely related to black walnut also produce juglone, although in limited quantities and include butternut or white walnut (Juglans cinerea), Persian walnut (Juglans regia) and many other related walnuts throughout Asia and South America.

Another example of a plant producing root exudates with known allelopathic activity is in wheat. Allelopathy in wheat appears to be associated with the presence of simple phenolic compounds including p-hydroxybenzoic, vanillic, p-coumaric, syringic and ferulic acids as well as the presence of hydroxamic acids (Yongqing, 2006). Sorghum roots exuded a mixture of biologically- active hydrophobic substances, one major component of which is known as sorgoleone, characterized as 2-hydroxy-5methoxy-3-pentadecatriene]-p-benzoquinone.

Sorgoleone has been characterized as a potent bioherbicide which is inhibitory to broadleaf and grass weeds at concentrations as low as $10 \mu \mathrm{M}$ in hydroponic bioassays (Xiaohan et al., 2004). Many plants also produce secondary metabolites that inhibit the growth of eight specific plants (autotoxicity). Autotoxicity has been widely observed in agricultural crops and weeds, as well as in some plants that inhabit natural systems. Phytotoxic root exudates appear to mediate autoinhibition in at least some of these species, including Asparagus officinalis (garden asparagus), Cucumis sativa (garden cucumber) (Yu et al., 2003) and Centaurea maculosa (spotted knapweed) (Perry et al., 2005).

\section{Root-microbe communication}

Interactions between plants and soil microbes are highly dynamic in nature and based on co-evolutionary pressures (Dobbelaere et al., 2003; Duffy et al., 2004; Klironomos, 2002; Morgan et al., 2005; Morrissey et al., 2004; Reinhart and Callaway, 2006). Consequently, it is not astonishing that rhizosphere microbial communities differ between plant species (Batten et al., 2006; Innes et al., 2004), between genotypes within species (Kowalchuk et al., 2006) and between different developmental stages of a given plant (Mougel et al., 2006; Wei-Hong et al., 2007). At a community scale, microbial diversity in the soil has been linked to plant diversity, though it is unclear whether this is through increased habitat heterogeneity, the increased plant biomass commonly observed with highly diverse plant communities or increased diversity of carbon substrates and signaling compounds provided by the plants.

The signal components largely responsible for these specific host-microbe relationships belong to a class of compounds termed flavonoids. Data on flavonoids as signaling compounds are available from several symbiotic and pathogenic plant-microbe interactions. More than 4000 different flavonoids have been identified in vascular plants, and a particular subset of them is involved in mediating host specificity in legumes (Perret 
et al., 2000). In several Fusarium plant interactions, an effect of flavonoids on micro- and macroconidia germination has been reported; however, nearly no data are available yet on hyphal growth and the role of flavonoids during infection. Moreover, to our knowledge scarce data are available about alterations of flavonoid level in plants infected by Fusarium (Siegrid et al., 2007). Iso-flavonoids are only found in members of the legume family. Daidzein and genistein, isoflavonoids produced by soybean (Glycine max), effectively induce Bradyrhizobium japonicum nod genes, but inhibit Sinorhizobium meliloti nod gene expression. S. meliloti nod genes are instead induced by luteolin (Juan et al., 2007). This specificity enables rhizobia to distinguish their hosts from other legumes. The specific flavonoid not only induces nod gene expression, but also rhizobial chemotaxis (Bais et al., 2006). Thus, further studies are needed to elucidate their exact role in this interaction. Striglactones only recently have been identified as important signals in the AMF-plant interaction and thus, are "hot issues" in mycorrhizal research. To our knowledge, no data are available yet about their implication as signaling compounds in other plant-microbe interactions.

Rhizobia-legume interactions are very specific, allowing specific rhizobial strains to nodulate with specific host legumes. S. meliloti effectively nodulates species of the Medicago, Melilotus and Trigonella genera, whereas Rhizobium leguminosarum bv viciae induces nodules in the Pisum, Vicia, Lens and Lathyrus genera (Bais et al., 2006). Scientists demonstrated that roots selectively secrete L-MA (malic acid) and effectively signal beneficial rhizobacteria establishes a regulatory role of root metabolites in recruitment of beneficial microbes, as well as underscores the breadth and sophistication of plantmicrobial interactions (Thimmaraju et al., 2008).

Brassicaceae have also been found to have a stimulatory effect on ectomycorrhizal fungi (Zeng et al., 2003). Few researchers demonstrates that two model plant species (Arabidopsis thaliana and Medicago truncatula) are able to maintain resident soil fungal populations, but unable to maintain nonresident soil fungal populations. This is mediated largely through root exudates: the effects of adding in vitro-generated root exudates to the soil fungal community were qualitatively and quantitatively similar to the results observed for plants grown in those same soils (Yanhong et al., 2009).

\section{APPROACHES OF REMEDIATION}

The rhizospheric bacteria are responsible for the elimination of the contaminants, while the roots are responsible for providing nutrients used by the microorganisms to proliferate. Then strategy was developed to select pollutant-degrading rhizobacteria that live on or are close to the root so that they can use root exudate as their major nutrient source. These authors developed a system to efficiently enrich such bacteria by starting from a crude mixture of bacteria from grass roots and subsequently, alternating between selecting for growth on the pollutant naphthalene and selecting for efficient colonization of grass roots. One of the resulting strains, Pseudomonas putida PCL1444, effectively utilizes root exudate, degrades naphthalene around the root, protects seeds from being killed by naphthalene and allows the plant to grow normally. Mutants unable to degrade naphthalene do not protect the plant (Yanhong et al., 2009).

Root exudates have the potential to increase the degradation of xenobiotics by the growth of soil microorganisms. Separating the chemical impact of the root exudates from any root surface phenomena is an important step in isolating a potential mechanism of phytoremediation. $\mathrm{Cu}$ binding to root exudates of two cultivated plants, wheat ( $T$. aestivum) and rape (B. napus) and two weeds associated with wheat, dog daisy (Matricaria inodora) and cornflower (Centaurea cyanus), was studied in vitro under hydroponic and sterile conditions (Sylvie et al., 2001). The amount of the organic compounds exuded by plant root is important in determining the extent of ion $\mathrm{Cu}$ as corresponded (Sylvie et al., 2001). Some worker conducted a glasshouse experiment using a root -bag technique to study the root exudates, rhizosphere $\mathrm{Zn}$ fractions and $\mathrm{Zn}$ concentrations and accumulations of two ryegrass cultivars (Lolium perenne L. Cvs. Airs and Tede) at different soil $\mathrm{Zn}$ levels and concluded that genotypic differences in $\mathrm{Zn}$ accumulations were mainly because of different root exudates and rhizosphere $\mathrm{Zn}$ fractions (Wei et al., 2007). An additional study concluded that the phytase activity in tobacco root exudates is exhibited by a purple acid phosphatase and its catalytic properties are pertinent to its role in mobilizing organic $P$ in soil (Lung et al., 2007).

Improved degradation of high molecular weight polycyclic aromatic hydrocarbons (PAH) during phytoremediation has provoked examinations of controlling plant/microbe interactions (Paquin et al., 2002). A number of scientist established chemotaxis of $\mathrm{PAH}$ degrading rhizosphere bacteria (Pseudomonas alcaligenes, Pseudomonas stutzeri and $P$. putida) to naphthalene, phenanthrene and root exudates (Ortega et al., 2003). Fascinatingly, the bacteria were repelled by anthracene and pyrene. The attraction of competent bacteria to the root zone may improve bioavailability and increase PAH degradation in the rhizosphere. Subjugation of the phenanthrene degrading activity of $P$. putida following exposure to root extracts and exudates recommended that enzyme induction may not occur during rhizodegradation of PAHs (Rentz et al., 2004). Related studies observed repression of $\mathrm{PAH}$ catabolic genes on a per cell basis and demonstrated greater naphthalene degradation by cultures grown on root products compared to naphthalene, supporting the notion that prolific microbial growth provides improved 
degradation in the rhizosphere (Kamath et al., 2004). However, high molecular weight (HMW PAHs do not serve as a carbon and energy sources for microbial populations during degradation (Yanzheng et al., 2010). Correlated scientist conducted a batch experiment to evaluate the impact of root exudates on the desorption of phenanthrene and pyrene in soils and showed that the increment of phenanthrene and pyrene desorption was always higher with the addition of citric and oxalic acid than with the same concentration of artificial root exudates (AREs), indicating that the effects of AREs on desorption may be dominantly due to the organic acids (Yanzheng et al., 2010).

Some researchers clearly observed through their research that benzo[a]pyrene, a HMW polycyclic aromatic hydrocarbon (PAH) was removed from solution by Sphingomonas yanoikuyae, while growing on root products as a primary carbon and energy source (Jeremy et al., 2004). Plant root extracts of osage orange (Maclura pomifera), hybrid willow (Salix alba-matsudana), or kou (Cordia subcordata) or plant root exudates of white mulberry (Morus alba) supported 15 to $20 \%$ benzo[a]pyrene removal over $24 \mathrm{~h}$ that was similar to a succinate grown culture and an unfed acetonitrile control (Yanzheng et al., 2010).

Another study shows that the sorghum root exudates have the activities of oxidase, peroxidase and tyrosinase. The activities of these enzymes were progressive as the soil phenanthrene concentration increased. Using lyophilized samples study, it was concluded that as a result of the enzymatic activity of the root exudates, some of the PAHs and products of PAH degradation were oxidized in the reaction mixture supplemented with the mediating agents, but that no oxidation was observed in the reaction mixtures without the mediators. The revealed enzymatic activity of the sorghum root exudates may indicate the involvement of the root -released oxidoreductases in rhizospheric degradation of $\mathrm{PAHs}$ and/or their derivatives (Muratovaa et al., 2009).

A different observation established that some chelaters have been shown to enhance the phytoextraction of metal from contaminated soil. Their results revealed that EDTA increased the ability of barnyard grass to take up $\mathrm{Cd}, \mathrm{Cu}$ and $\mathrm{Pb}$, but that it resulted in increased soil leaching (Kim et al., 2009). Conversely, citric acid induced the removal of $\mathrm{Cd}, \mathrm{Cu}$ and $\mathrm{Pb}$ from soil without increasing the risk of leaching. Furthermore, Echinochloa crusgalli showed no signs of phytotoxicity in response to treatment with citric acid, whereas its shoot growth decreases in response to treatment with EDTA. One more study shows that the maize root exudates cannot enhance desorption under abiotic condition with the addition of $\mathrm{NaN}_{3}$ and can promote desorption of phenanthrene in soils without the addition of $\mathrm{NaN}_{3}$ (Yanzheng et al., 2010).

Environmental contamination due to anthropogenic and natural sources is increasing day by day because of increase in population, industrialization and urbanization. Advances in science and technology, since industrial revolution has also increasingly enabled humans to exploit natural resources and cause damage to the environment. The ideal solution for pollution abatement is bioremediation, the most effective innovative technology to come along that uses biological systems for treatment of contaminants. Although, this novel and recent technology is a multidisciplinary approach, its central thrust depends on microbiology. This technology includes biostimulation (stimulating viable native microbial population), bioaugmentation (artificial introduction of viable population), bioaccumulation (live cells), biosorption (dead microbial biomass), phytoremediation (plants) and rhizoremediation (plant and microbe interaction). Rhizoremediation, which is the most evolved process of bioremediation, involves the removal of specific contaminants from waste product of contaminated sites by mutual interaction of plant roots and suitable microbial flora.

\section{FUTURE PROSPECTS}

The main aim of this paper was to provide the information to cultivate modified plants that are capable of absorbing more nutrients, detoxifying soils more efficiently or more effectively warding off persistent weeds and pathogenic microbes. Bioremediation activity through root exudates is stimulated by supplementing nutrients (nitrogen and phosphorus), electron acceptors (oxygen) and substrates (methane, phenol and toluene), or by introducing microorganisms with desired catalytic capabilities. Plant and soil microbes develop a rhizospheric zone (highly complex symbiotic and synergistic relationships), which is also used as a tool for accelerating the rate of degradation or to remove contaminants. With the exciting new development in this field and focus on interdisciplinary research and using it on gaining the fundamental knowledge necessary to overcome the obstacles facing current technologies and also with respect to ethical, legal and social issues involved, this technology will go a long way in cleaning the environment in the near future.

\section{REFERENCES}

Albert DR (1969). Plant root exudates. Bot. Rev. 35(1): 35-57.

Alexa NS, Haig T, James E (2004). Evaluation of putative allelochemicals in rice root exudates for their role in the suppression of arrowhead root growth. J. Chem. Ecol., 30(8): 1663-1678.

Antonio E, Apariciob MF, Cimminoa A, Rubialesb D, Andolfia A, Mottac A (2009). Peagol and peagoldione, two new strigolactone-like metabolites isolated from pea root exudates. Tetrahedron Lett. 50 : 6955-6958.

Bacilio M, Flores AV, Valle VM, Pérez A, Zepeda A, Zenteno E (2001). Endophytic bacteria in rice seeds inhibit early colonization by Azospirillum brasilense. Soil Biol. Biochem., 33: 167-172.

Bacilio JM, Aguilar FS, Ventura ZE, Perez CE, Bouquelet S, Zenteno E (2002). Chemical characterization of root exudates from rice (Oryza sativa) and their effects on the chemotactic response of endophytic 
bacteria. Plant Soil, 249: 271-277.

Bais HP, Broeckling CD, Vivanco JM (2008). Root exudates modulate plant-microbe interactions in the rhizosphere in secondary metabolites in soil ecology. Soil Biol., 14: 241-252.

Bais HP, Park SW, Weir TL, Callaway RM, Vivanco JM (2004). How plants communicate using the underground information superhighway. Trend Plant Sci., 9: 26-32.

Bais HP, Weir TL, Perry LG, Gilroy S, Vivanco JM (2006). The role of root exudates in rhizosphere interactions with plants and other organisms. Ann. Rev. Plant. Biol., 57: 233-266.

Bais HP, Walker TS, Stermitz FR, Hufbauer RA, Vivanco JM (2002). Enantiomeric-dependent phytotoxic and antimicrobial activity of $( \pm)$ catechin. A rhizosecreted racemic mixture from spotted knapweed. Plant. Physiol., 128: 1173-79.

Batten KM, Scow KM, Davies KF, Harrison SP (2006). Two invasive plants alter soil microbial community composition in serpentine grasslands. Biol. Inv., 8: 217-230.

Benhamou N, Kloepper JW, Hallman QA, Tuzun S (1996). Induction of defense-related ultrastructural modifications in pea root tissues inoculated with endophytic bacteria. Plant Physiol., 112: 919-929.

Bertin C, Yang XH, Weston LA (2003). The role of root exudates and allelochemicals in the rhizosphere. Plant Soil, 256: 67-83.

Blaylock MSDE, Dushenkv S, Zakharova O, Gussman C, Kapulnik Y, Ensley B, Raskin E (1997). Enhanced accumulation of $\mathrm{Pb}$ in Indian mustard by soil-applied chelating agents, Environ. Sci. Technol., 31: 860-865.

Broeckling CD, Broz AK, Bergelson J, Manter DK, Vivanco JM (2008). Root exudates regulate soil fungal community composition and diversity. Appl. Environ. Microbiol., 74: 738-744.

Dayakar VB, Vivanco JM (2009). Regulation and function of root exudates. Plant Cell Environ. 32(6): 666 - 681.

Dobbelaere S, Vanderleyden J, Okon Y (2003). Plant growth-promoting effects of diazotrophs in the rhizosphere. Crit. Rev. Plant. Sci., 22: 107-149.

Duffy B, Keel C, Defago G (2004). Potential role of pathogen signaling in multitrophic plant-microbe interactions involved in disease protection. Appl. Environ. Microbiol., 70: 1836-1842.

Hale MG, Moore LD (1979). Factors affecting root exudation. Adv. Agron., 31: 93-124.

Hallmann J, Hallmann QA, Mahaffee AF, Kloepper JW (1997). Bacterial endophytes in agricultural crops. Can. J. Microbiol., 43: 895-914.

Hees van PAW, Vinogradoff SI, Edwards AC, Godbold DL, Jones DL (2003). Low molecular weight organic acid adsorption in forest soils: effects on soil solution concentrations and biodegradation rates. Soil Biol. Biochem., 35: 1015-1026.

Hiltner L (1904). Uber neuere erfahrungen und probleme auf dem gebiet der boden bakteriologie und unter besonderer berucksichtigung det grundungung und branche. Arb. Deut. Landw. Ges. 98: 59-78.

Husain SS, Mckeen WE (1963). Interactions between strawberry roots and Rhizoctonia fragariae. Phytopathol. 53: 541-545.

Hutsch BW, Augustin J, Merbach W (2000). Plant rhizodeposition an important source for carbon turnover in soils. J. Plant Nut. Soil Sci., 165: 397-407.

Innes L, Hobbs PJ, Bardgett RD (2004). The impacts of individual plant species on rhizosphere microbial communities in soils of different fertility. Biol. Fertil. Soils, 40: 7-13.

Jeremy A, Rentza PJ, Alvarezb J, Jerald LS (2004). Benzo[a]pyrene cometabolism in the presence of plant root extracts and exudates: implications for phytoremediation. Environ. Pollut., 136: 477-484.

Jones DL, Darrah PR (1995). Influx and efflux of organic acids across the soil-root interface of Zea mays $L$. and its implications in rhizosphere C flow. Plant Soil, 173: 103-109.

Jose S, Gillespie AR (1998). Allelopathy in black walnut (Juglans nigra L.) alley cropping. I. Spatio-temporal variation in soil juglone in a black walnut-corn (Zea mays L.) alley cropping system in the Midwestern. Plant Soil, 203: 191-197.

Juan Z, Subramanian S, Zhang Y, Yu O (2007). Flavone Synthases from medicago truncatula are flavanone-2-hydroxylases and are important for nodulation. Plant Physiol., 144: 741-751.

Kamath R, Schnoor JL, Alvarez PJJ (2004). Effects of plantderived substrates on expression of catabolic genes using a nah-lux reporter.
Environ. Sci. Technol., 38: 1740-1745.

Kang S, Mills AL (2004). Soil bacterial community structure changes following disturbance of the overlying plant community. Soil Sci., 169(1): 55-65.

Kim SH, Park JS, Lee IS (2009). Characterization of cadmium binding ligands from roots of Echinochloa crusgalli var. frumentacea, J. Plant Biol., 52: 167-170.

Klironomos JN (2002). Feedback with soil biota contributes to plant rarity and invasiveness in communities. Nature, 417: p. 67.

Kocacali I, Ceylan M, Terzi I (2009). Effects of juglone on seedling growth in intact and coatless seeds of cucumber (Cucumis sativus $\mathrm{cv}$. Beith alpha). Sci. Res. Essay, 4(1): 039-041.

Kong $\mathrm{CH}$, Liang WJ, Xu XH, Hu F, Wang P, Jiang Y (2004). Release and activity of allelochemicals from allelopathic rice seedlings. J. Agric. F. Chem., 52: 2861-2865.

Kowalchuk GA, Hol WHG, Van Veen JA (2006). Rhizosphere fungal communities are influenced by Senecio jacobaea pyrrolizidine alkaloid content and composition. Soil Biol. Biochem., 38: 28522859.

Kuiper I, Lagendijk EL, Bloemberg GV, Lugtenberg BJJ (2004). Rhizoremediation: a beneficial plant-microbe interaction. Mol. PlantMicrobe Interact., 17: 6-15.

Kuzyakov Y, Raskatov A, Kaupenjohann M (2003). Turnover and distribution of root exudates of Zea mays. Plant Soil., 254: 317-327.

Lugtenberg BJJ, Kravchenko LV, Simons M (1999). Tomato seed and root exudate sugars: composition, utilization by Pseudomonas biocontrol strains and role in rhizosphere colonization. Environ. Microbiol., 1: 439-446.

Lung SC, Leung A, Kuang R, Wang Y, Leung P, Lim BL (2007). Phytase activity in tobacco (Nicotiana tabacum) root exudates is exhibited by a purple acid phosphatase. Phytochemistry, 69(2): 36573.

Morgan JAW, Bending GD, White PJ (2005). Biological costs and benefits to plant-microbe interactions in the rhizosphere. J. Exp. Bot., 56: $1729-1739$.

Morrissey JP, Dow JM, Mark GL, Gara FO (2004). Are microbes at the root of a solution to world food production? Rational exploitation of interactions between microbes and plants can help to transform agriculture. EMBO Rep., 5: 922-926.

Mougel C, Offre P, Ranjard L, Corberand T, Gamalero E, Robin C, Lemanceau $P$ (2006). Dynamic of the genetic structure of bacterial and fungal communities at different developmental stages of Medicago truncatula Gaertn. cv. Jemalong line J5. N. Phytol., 170: 165-175.

Muratovaa A, Pozdnyakovaa N, Golubeva S, Wittenmayerb L, Makarova O, Merbachb W, Turkovskayaa O (2009). Oxidoreductase activity of sorghum root exudates in a phenanthrene-contaminated environment Chemosph. 74(8): 1031-1036.

Narasimhan K, Basheer C, Bajic V, Swarup S (2003). Enhancement of plant-microbe interactions using a rhizosphere metabolomics-driven approach and its application in the removal of polychlorinated biphenyls. Plant Physiol., 132: 146-153.

Nguyen C (2003). Rhizodeposition of organic C by plants: mechanisms and controls. Agron. 23: 375-396.

Nimbal Cl, Pedersen JF, Yerkes CN, Weston LA, Weller SC (1996). Phytotoxicity and distribution of sorgoleone in grain sorghum germplasm. J. Agric. Food. Chem., 44: 1343-1347.

Norman AG (1961). Microbial products affecting root development. Trans. 7th Congr. Wiscons. Int. Soil Sci. Soc., 2: 531-536.

Ortega JJ, Al Marchenko, AV Vorobyov, RV Borovick (2003). Chemotaxis in polycyclic aromatic hydrocarbon-degrading bacteria isolated from coal-tar and oil-polluted rhizospheres. FEMS. Microb. Econ., 44: 373-381.

Paquin D, Ogoshi R, Campbell S, Qx L (2002). Bench-scale phytoremediation of polycyclic aromatic hydrocarbon-contaminated marine sediment with tropical plants. Int. J. Phytol., 4: 297-313.

Perret X, Staehelin C, Broughton WJ (2000). Molecular basis of symbiotic promiscuity. Microbiol. Mol. Biol. Rev., 64: 180-201.

Perry LG, Thelen GC, Ridenour WM, Weir TL, Callaway RM (2005). Dual role for an allelochemical: $( \pm)$-catechin from Centaurea maculosa root exudates regulates conspecific seedling establishment. J. Ecol., 93: 1125-1136. 
Philippe $H$ (2006). Rhizosphere: a new frontier for soil biogeochemistry. J. Geol. Exp., 88: 1-3, 210-213.

Pleban S, Ingel F, Chen I (1995). Control of Rhizoctonia solani and Sclerotium rolfsii in the greenhouse using endophytic Bacillus spp. Eur. J. Plant. Pathol., 101: 665-672.

Rangarajan S, Loganathan P, Saleena M, Nair S (2001). Diversity of Pseudomonads isolated from three di variant plant rhizospheres. J. Appl. Microbiol., 91: 742-749.

Reinhart KO, Callaway RM (2006). Soil biota and invasive plants. N. Phytol., 170: 445-457.

Rentz JA, Alvarez PJJ, Schnoor JL (2004). Repression of Pseudomonas putida phenanthrene-degrading activity by plant root extracts and exudates. Environ. Microbiol., 6: 574-583.

Ross IL, Alami Y, Harvey PR, Achouak W, Ryder MH (2000). Genetic diversity and biological control activity of novel species of closely related Pseudomonads isolated from wheat weld soils in South Australia. Appl. Environ. Microbiol., 66: 1609-1616.

Rovira AD (1959). Plant root excretions in relation to the rhizosphere effect. I. The nature of root exudate from oats and peas. Plant Soil, 7: 178-194.

Shukla KP, Singh NK, Sharma S (2010). Bioremediation: Developments, Current Practices and Perspectives. Gen. Eng. Biotechnol. J., 3: 1-20.

Siegrid S, Lendzemo V, Langer I, Schweiger P, Khaosaad T, Toussaint JP, Vierheilig H (2007). Flavonoids and strigolactones in root exudates as signals in symbiotic and pathogenic plant-fungus interactions. Molecule, 12: 1290-1306.

Stermitz FR, Bais HP, Foderaro TA, Vivanco JM (2003). 7, 8Benzoflavone: a phytotoxin from root exudates of invasive Russian knapweed. Phytochemistry, 64: 493-97.

Stintzi A, Browse J (2000). The Arabidopsis male-sterile mutant, opr3, lacks the 12-oxophytodienoic acid reductase required for jasmonate synthesis. Proc. Natl. Acad. Sci., 97: 10625-10630.

Stotz HU, Pittendrigh BR, Kroymann J, Weniger K, Fritsche J, Bauke A, Mitchell OT (2000). Induced plant defense responses against chewing insects, ethylene signaling reduces resistance of Arabidopsis against Egyptian cotton worm but not diamondback moth. Plant Physiol., 124: 1007-1018.

Sylvie D, Morel JL, Jacobson A, Bitton G (2001). Copper binding capacity of root exudates of cultivated plants and associated weeds. Biol. Fertil. S. 34: 230-234.

Thimmaraju R, Czymmek KJ, Pare PW, Bais HP (2008). Root-secreted malic acid recruits beneficial soil bacteria. Plant Physiol., 148: 15471556.

Torsvik V, Sorheim R, Goksoyr J (1996). Total bacterial diversity in soil and sediment communities - a review. J. Ind. Microbiol., 17: 170178.

Toal ME, Yeomans C, Killham K, Meharg AA (2000). A review of rhizosphere carbon flow modelling. Plant Soil, 222: 263-281.
Uren NC (2001). Types, amounts, and possible functions of compunds released into the rhizosphere by soil-grown plants. Eds. Pinton, R, Varanini, Z, Naminipieri, P The Rhizosphere Biochemistry and organic Substances at the Soil Plant Interface, 19-40. New York, USA, Marcel Dekker.

Vancura V, Hovadik A (1965). Composition of root exudates in the course of plant development. Plant Microb. Relat., pp. 21-25.

Vancura V (1964). Root exudates of plants and analysis of root exudates of barley and wheat in their initial phases of growth. Plant Soil, 21: 231-248.

Vivanco JM, Bais HP, Stermitz FR, Thelen GC, Callaway RM (2004). Biogeographical variation in community response to root allelochemistry: novel weapons and exotic invasion. Ecol. Lett., 7: 285-292.

Wei HXU, Huai L, Mac QF, Xiongd ZT (2007). Root exudates, rhizosphere $\mathrm{Zn}$ fractions, and $\mathrm{Zn}$ accumulation of ryegrass at different soil Zn levels1. Pedosph. 17(3): 389-396.

Weir TL, Park SW, Vivanco JM (2004). Biochemical and physiological mechanisms mediated by allelochemicals. Curr. Opin. Plant Biol., 7: 472-479

Wu HW, Haig T, Pratley J, Lemerle DM (2000). Allelochemicals in wheat (Triticum aestivum L.): variation of phenolic acids in root tissues. J. Agric. Food Chem., 48: 5321-5325.

Xiaoe YF, Zhenli H, Stoffellab PJ (2005). Molecular mechanisms of heavy metal hyperaccumulation and phytoremediation. J. T. Elem. Med. Biol., 18(4): 27: 339-353.

Xiaohan Y, Brian E, Scheffler, Weston LA (2004). SOR1, a gene associated with bioherbicide production in sorghum root hairs. J. Exp. Bot., 55(406): 2251-2259.

Yanhong, ZHU, Shuzhen Z, Honglin H, Bei W (2009). Effects of maize root exudates and organic acids on the desorption of phenanthrene from soils. J. Environ. Sci., 21(7): 920-926.

Yanzheng, Lili GR, Wanting L, Gonga S, Suna B, Zhanga Y (2010). Desorption of phenanthrene and pyrene in soils by root exudates. Bioresour. Technol. 101(4): 1159-1165.

Yongqing MA (2006). Allelopathic studies of common wheat (Triticum aestivum L.) W. Biol. Mol. 5(3): 93-104.

Yu JQ, Ye SF, Zhang MF, Hu WH (2003). Effects of root exudates and aqueous root extracts of cucumber (Cucumis sativus) and allelochemicals, on photosynthesis and antioxidant enzymes in cucumber. Biochem. Syst. Ecol., 31: 129-39.

Zeng RS, Mallik RS, Setliff E (2003). Growth stimulation of ectomycorrhizal fungi by root exudates of Brassicaceae plants: role of degraded compounds of indole glucosinolates. J. Chem. Ecol., 29: 1337-1355. 